\title{
Effects of Hypothyroidism on Jejunal Mucosal Function: Study by In Situ Luminal Perfusion in Rats ${ }^{1}$
}

\author{
MOSHE BERANT, ERIC DIAMOND, WALEED MABRIKI, AND OFER BEN-YITZHAK \\ Department of Pediatrics [M.B., W.M.], Laboratory of Clinical Biochemistry [E.D.], and Institute of Pathology \\ [O.B.-Y.], Rambam Medical Center and Technion-Faculty of Medicine, Haifa, Israel
}

\begin{abstract}
To assess the effects of hypothyroidism (HT) on small-intestinal function, HT was induced in rats (120$150 \mathrm{~g}$ ) by methimazole in drinking water. After 6 wk of methimazole, intestinal absorption studies were performed in $\mathrm{HT}$ and in control (C) rats by in situ luminal perfusion of a $20-\mathrm{cm}$ proximal jejunal loop with a bicarbonate buffer containing sodium, glucose or fructose, glycine or lysine, and phenol red as a nonabsorbable marker for determination of water fluxes. Mucosa from the perfused segment was taken for assay of disaccharidases and ATPases and for light and electron microscopy. Compared with $\mathrm{C}$ rats, HT rats had significantly lower jejunal transport rates of water $(2.54 \pm 0.36$ versus $5.02 \pm 0.7 \mu \mathrm{L} / \mathrm{min} / \mu \mathrm{g}$ mucosal protein, $p<0.03)$, sodium $(37.1 \pm 10.3$ versus $102.7 \pm$ $18.6 \mu \mathrm{mol} / \mathrm{min} / \mu \mathrm{g}$ protein, $p<0.05)$, and glucose $(1.49 \pm$ 0.28 versus $5.17 \pm 0.82 \mu \mathrm{mol} / \mathrm{min} / \mu$ g protein, $p<0.02$ ). A reduction in glycine transport was also observed but did not attain statistical significance $(p=0.058)$. Fructose and lysine transport was unchanged. Mucosal sucrase and lactase activities were similar in both groups, but $\mathrm{Na}, \mathrm{K}$ ATPase was significantly lower in $\mathrm{HT}$ rats $(1.17 \pm 0.3$ versus $4.03 \pm 1.5 \mu \mathrm{mol}$ inorganic phosphate $/ \mathrm{h} / \mathrm{mg}$ protein; $p<0.05$ ), with a diminution of ouabain binding sites by 41.5\%. Light microscopy of jejunal mucosa from HT rats did not differ from that from $\mathrm{C}$ rats; electron microscopy showed mild mitochondrial swelling in HT enterocytes. A group of HT rats were treated with L-thyroxine during 4 wk; these rats had absorption rates, mucosal enzyme activities, ouabain binding, and mucosal morphology not different from $C$ rats. We conclude that $H T$ in the rat can depress jejunal mucosal $\mathrm{Na}, \mathrm{K}-\mathrm{ATPase}$ activity and reduce Na,K-ATPase-dependent transport without structural changes other than mild enterocyte mitochondrial swelling. A diminished jejunal functional capacity might add a nutritional component to the growth retardation that is observed in HT. (Pediatr Res 34: 79-83, 1993)
\end{abstract}

\section{Abbreviations}

HT, hypothyroid(ism)

HT\&T, thyroxine-treated hypothyroidism

C, control

Na,K-ATPase, sodium-potassium activated adenosine triphosphatase

Received September 1, 1992; accepted February 10, 1993.

Correspondence: Moshe Berant, M.D., Department of Pediatrics, Rambam Medical Center, Haifa 31096, Israel.

Supported in part by the New York Metropolitan Research Fund through Technion-VPR fund no 080-0326.

'Presented in part at the 25th Annual Meeting of the European Society for Pediatric Gastroenterology and Nutrition, Brussels, Belgium, May 27-30, 1992.
HT in childhood is notably associated with growth retardation. Nutritional deficits may contribute to this growth failure through the ill effects that HT may have on the gastrointestinal system. Whereas diarrhea and malabsorption have been considered rare in HT they do indeed occur and may be more common than is generally appreciated (1). HT may induce disturbances of intestinal motility (2) that can lead to a "contaminated gut" situation and its associated derangements (3). In addition, HT may impair nutrition by causing a decrease in appetite and food intake, alterations of mesenteric blood supply, and a reduction in epithelial mass (4). HT also appears to affect small-intestinal absorptive processes, but the reported data in this regard are inconsistent and conflicting, mainly because of heterogeneity of investigative models and methodologic diversity $(2,5-8)$.

We have investigated the effects of HT on jejunal mucosal transport function by in situ luminal perfusion studies in rats.

\section{MATERIALS AND METHODS}

The study was approved by the Laboratory Animal Ethics Committee of Technion-Faculty of Medicine, and the rules and guidelines of the Committee were strictly followed.

HT was induced in 32 male Sprague-Dawley rats $(120-150 \mathrm{~g})$ by administration of methimazole, $100 \mathrm{mg} / \mathrm{kd} / \mathrm{d}$, in drinking water during $6 \mathrm{wk}$ (HT rats). Of these HT rats, 16 (HT\&T rats) were treated with sodium L-thyroxine, $4 \mu \mathrm{g} / \mathrm{kg} / \mathrm{d}$, during a 4 -wk period. A group of 28 healthy rats served as controls (C rats). Gavage feeding assured that the food intake of the rats in all three groups would be similar.

Figure 1 shows the weight curve (mean) of each group of rats: those receiving methimazole stopped gaining weight by the 2 nd wk of treatment; supplementation with thyroxine provoked an increase in the rate of weight gain in HT rats. The experimental studies were conducted after 6 wk of methimazole administration (HT along with $\mathrm{C}$ rats) and after $4 \mathrm{wk}$ of thyroxine supplementation (HT\&T with $C$ rats). Serum free-thyroxine values (ng/dL; mean $\pm \mathrm{SD}$ ) of the rats on the day of the experiment were as follows: HT rats, $0.4 \pm 0.06 ;$ HT\&T rats, $1.2 \pm 0.13 ; \mathrm{C}$ rats, 1.1 $\pm 0.15(p<0.05$ HT versus HT\&T and C).

We examined jejunal mucosal transport capacity, brush-border enzymes and mucosal ATPase activity, kinetics of mucosal ouabain binding, and mucosal appearance on light and electron microscopy.

Jejunal transport studies. The rats were anesthetized with Pentothal $4 \mathrm{mg} / 100 \mathrm{~g}$ body weight intraperitoneally. The proximal jejunum was exposed by a midline abdominal incision, and a $20-\mathrm{cm}$ segment just distal to the ligament of Treitz was cannulated at its proximal and distal ends for in situ luminal perfusion. The test solution was driven at an average rate of 0.3 $\mathrm{mL} / \mathrm{min}$ by means of a Harvard peristaltic pump (Harvard Apparatus Co., Millis, MA). The perfusion solution consisted of Krebs-Henseleit bicarbonate buffer containing the following (in 


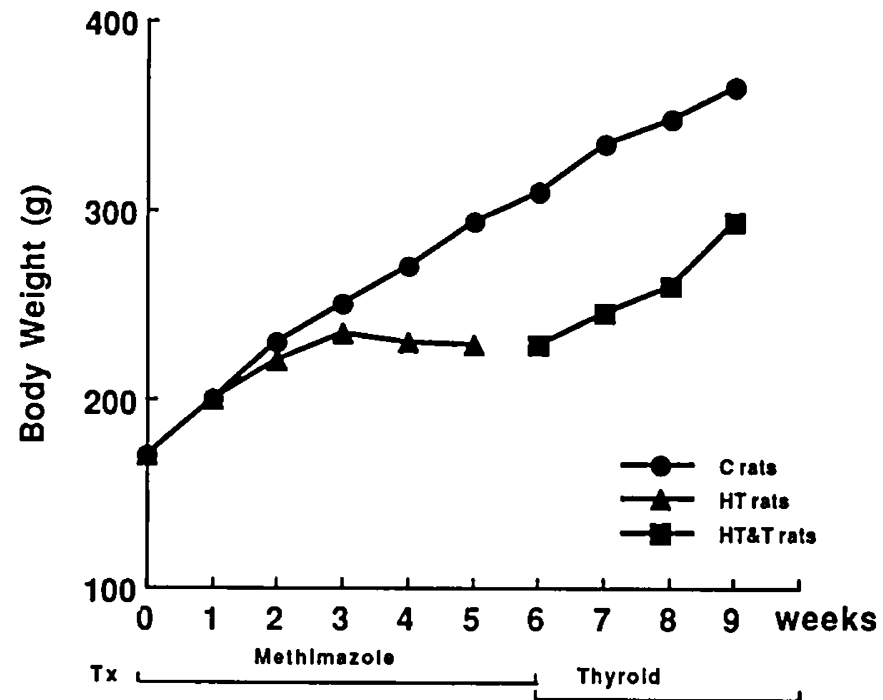

Fig. 1. Mean weight curves of the three groups of rats. Induction of HT arrested weight gain; subsequent thyroxine treatment (HT\&T) caused catch-up growth.

mmol/L): sodium, 123; potassium, 4; either glucose or fructose, 45; and either glycine or the dibasic amino acid lysine, 10, labeled with $20 \mu \mathrm{Ci} / \mathrm{L}\left[{ }^{3} \mathrm{H}\right.$ ]amino acid (New England Nuclear, Boston, MA). Phenol red, $20 \mathrm{mg} / \mathrm{L}$, was added as a nonabsorbable marker for estimation of water fluxes (9). The solution was continuously bubbled with a mixture of $95 \% \mathrm{O}_{2}$ and $5 \% \mathrm{CO}_{2}$, yielding a $\mathrm{PCO}_{2}$ of about $40 \mathrm{~mm} \mathrm{Hg}(5.3 \mathrm{kPa})$; the $\mathrm{pH}$ was kept at 7.4 and the osmolarity at $280 \mathrm{mosmol} / \mathrm{L}$. The sugars and amino acids were tested in groups of seven to eight rats.

After 30 min of equilibration with free luminal perfusion, four 15-min aliquots of effluent perfusate were collected from the distal end of the jejunal loop for measurement of water, sodium, glucose or fructose, and glycine or lysine content. The jejunal transport rates of sodium, glucose, fructose, glycine, and lysine were calculated from the differences in their concentration in the perfusion solution and in the effluent and were corrected for water flux, mucosal protein concentration ( $\mu \mathrm{g}$ protein $/ \mathrm{mg}$ wet tissue/cm jejunum), and pumping rate. The concentration of sodium was measured by an ion-specific electrode (Beckman Instruments, ASTRA analyzer, High Wycombe, Bucks, UK); fructose was measured by the method of Davis and Gander (10); glycine and lysine were determined by ${ }^{3} \mathrm{H}$ liquid scintillation counting (Beckman LS 230); and phenol red was measured by the method of Miller and Schedl (9). The recovery of phenol red in all samples was $98 \pm 4.2 \%$ (mean \pm SD).

Mucosal enzymes. After completion of the perfusion period, the experimental loop was cut open longitudinally along the antimesenteric aspect; the mucosa was carefully scraped off with a glass slide, and a specimen was immediately frozen and stored at $-60^{\circ} \mathrm{C}$ for $<1$ wk before the assay of lactase and sucrase activity. The remaining fresh specimen was used for the assay of $\mathrm{Na}, \mathrm{K}-\mathrm{ATPase}$ activity and for $\left[{ }^{3} \mathrm{H}\right]$ ouabain binding. Specific lactase and sucrase activities were determined in mucosal specimens obtained on the same day from experimental and control rats, by the method of Dahlqvist (11). Protein content of the mucosa was determined by the method of Bradford (12). Na,KATPase was assayed in fresh mucosal specimens that were immediately homogenized at 0 to $4^{\circ} \mathrm{C}$ in a solution containing 1 $\mathrm{mM}$ EDTA and $10 \mathrm{mM}$ Tris- $\mathrm{HCl}$ buffer ( $\mathrm{pH} 7.5$ ), using a PotterElvehjem glass homogenizer with a motor-driven Teflon pestle. The final concentration of the homogenate was $30 \mathrm{mg}$ of tissue per $\mathrm{mL}$ of buffer solution.

The homogenates were incubated in an ATP-containing medium for starting the enzymatic reaction, and ATPase activity ( $\mu \mathrm{mol}$ inorganic phosphate released per $\mathrm{mg}$ protein $/ \mathrm{h}$ ) was assayed in the presence and absence of ouabain $(1 \mathrm{mM})$ to differ- entiate between total, $\mathrm{Mg}$, and $\mathrm{Na}, \mathrm{K}-\mathrm{ATPases}$, according to the method of Kramer et al. (13). The incubation medium contained a final concentration of $3 \mathrm{mM} \mathrm{ATP}, 3 \mathrm{mM} \mathrm{Mg} \mathrm{Mg}^{2+}, 100 \mathrm{mM}$ sodium, $20 \mathrm{mM}$ potassium, and $100 \mathrm{mM}$ imidazole- $\mathrm{HCl}$ buffer at $\mathrm{pH} 7.2$.

$\left[{ }^{3} \mathrm{H}\right]$ ouabain binding to $\mathrm{Na}, \mathrm{K}-\mathrm{ATPase}$ was studied using an adaptation of the method described by Yamamoto et al. (14). The freshly prepared homogenates (approximately $3 \mathrm{mg}$ of tissue $/ \mathrm{mL}$ ) were incubated with $10 \mathrm{nM}\left[{ }^{3} \mathrm{H}\right]$ ouabain in the presence and absence of different concentrations of nonradioactive ouabain in a medium containing $200 \mathrm{mM} \mathrm{NaCl}, 5 \mathrm{mM} \mathrm{MgCl}, 5$ $\mathrm{mM}$ Tris-ATP, and $5 \mathrm{mM}$ Tris- $\mathrm{HCl}$ buffer at $\mathrm{pH}$ 7.5. The medium was preincubated at $37^{\circ} \mathrm{C}$ for $5 \mathrm{~min}$; the binding reaction was started by addition of the homogenate and was allowed to proceed for $15 \mathrm{~min}$ at $37^{\circ} \mathrm{C}$. The aliquots were filtered through type AA 8- $\mu \mathrm{m}$-pore nitrocellulose filters (Millipore Corp., Bedford, MA) for separation of free from tissue-bound ouabain. The filters were dissolved in ethyleneglycol monomethyl ether, and the radioactivity was measured by liquid scintillation spectrometry. Specific, ATP-dependent uptake was calculated by substracting nonspecific $\left[{ }^{3} \mathrm{H}\right]$ ouabain uptake that occurred in the absence of ATP from the total uptake as observed in the presence of ATP. The data were analyzed by constructing Scatchard plots for estimation of dissociation constants and ouabain binding sites.

Mucosal structure and ultrastructure. Samples from the wall of the jejunum just distal to the perfused loop were fixed in $2.5 \%$ glutaraldehyde buffered with $0.1 \mathrm{mM}$ cacodylate at $\mathrm{pH} 7.3$ and prepared for light and electron microscope study by standard methods.

Statistical analysis. Statistical analysis of the data was done by analysis of variance for repeated measures and by $t$ test where appropriate. A $p$ value of 0.05 or less was considered statistically significant.

\section{RESULTS}

Mucosal mass. The wet weight (mean $\pm \mathrm{SD}$ ) of the mucosal scrapings per $\mathrm{cm}$ of jejunum from the HT, HT\&T, and $\mathrm{C}$ rats was $14 \pm 1.67,13.57 \pm 2.01$, and $13.2 \pm 1.86 \mathrm{mg}$, respectively; the protein content per mg mucosa was $0.041 \pm 0.002,0.052 \pm$ 0.003 , and $0.058 \pm 0.003 \mu \mathrm{g}$, respectively. Although HT rats had a relatively lower mucosal protein content, the differences were not statistically significant, perhaps due to the short duration of the HT state of the HT rats.

Mucosal transport. The jejunal transport rates of water, sodium, and glucose, were significantly lower in the HT rats than in controls $(p<0.03, p<0.05$, and $p<0.02$, respectively) (Fig. 2 ). The absorption rates of glycine were also lower in the HT rats, but the difference was not statistically significant $(p=$ 0.058 ). The transport rates of fructose and lysine were similar in both groups. The jejunal transport capacity of the HT\&T rats was not different from that of $\mathrm{C}$ rats.

Mucosal enzymes. The activity of the brush border enzymes lactase and sucrase, and mucosal "total" ATPase activity, was similar in the HT, HT\&T, and C rats. Mucosal Na,K-ATPase activity in the HT\&T rats was not different from that in the $C$ rats. In contrast, Na,K-ATPase activity in the jejunal mucosa of HT rats was significantly decreased $(p<0.05)$ (Fig. 3). Scatchard plots, derived from data obtained by estimation of ATP-dependent $\left[{ }^{3} \mathrm{H}\right]$ ouabain binding by the mucosal homogenates, demonstrated a significant reduction in the number of binding sites for ouabain $(p<0.02)$ in the mucosa of the HT rats, as compared with the HT\&T and $C$ rats.

Binding site concentration and $k_{d}$ were estimated for each rat jejunal homogenate from the intercept and the slope of the linear regression line fitted to a plot for each experiment by the leastsquares method. The averaged data are shown in Table 1. Whereas $k_{d}$ for ouabain, which expresses affinity, was similar in the mucosal preparations of all three groups, the number of binding sites for ouabain in the HT rats was lower than in the 
A

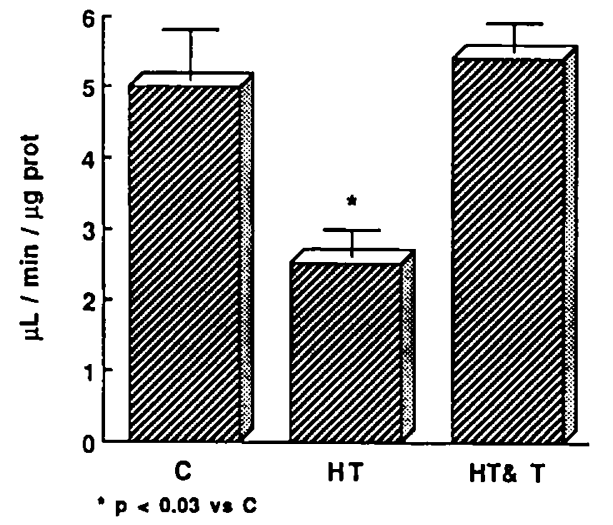

B
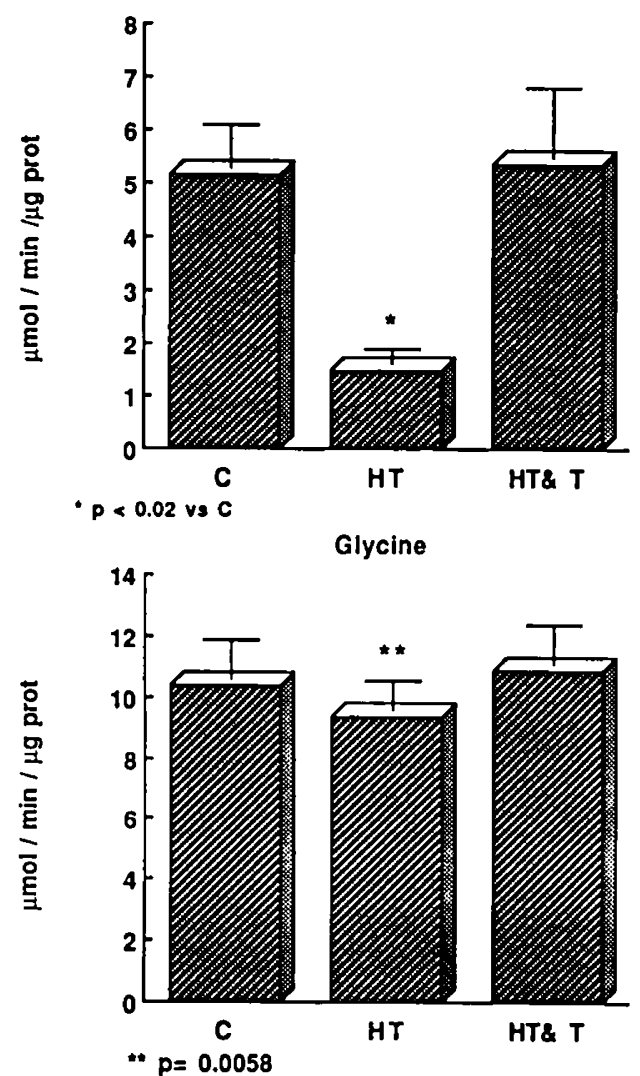

Sodium

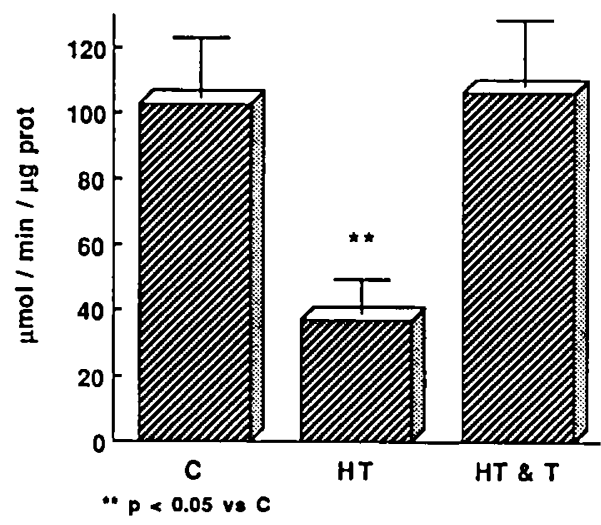

Fructose
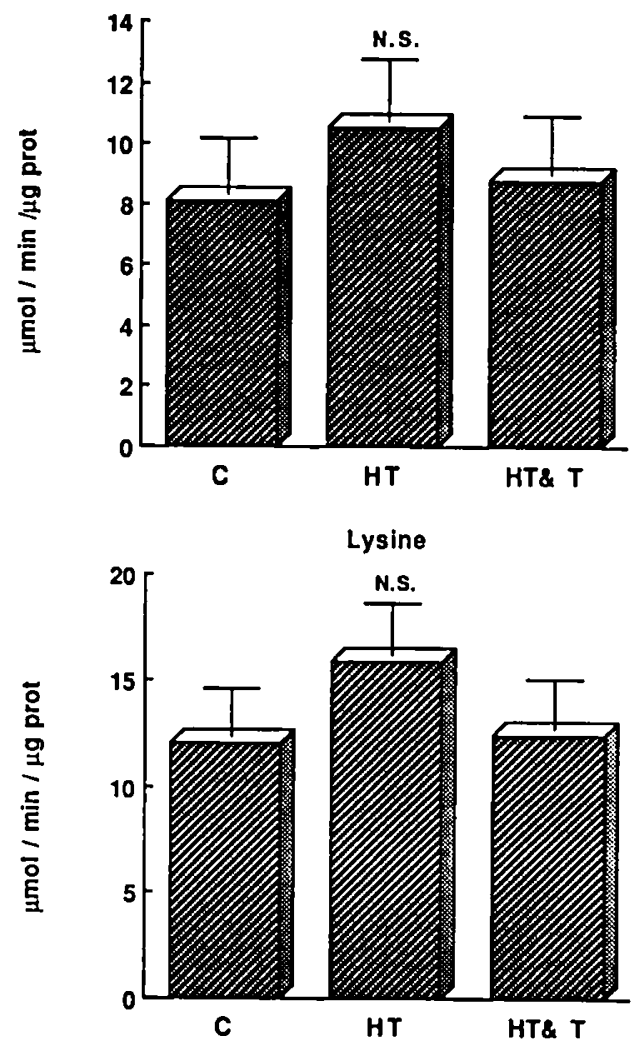

Fig. 2. Jejunal transport rates (mean $\pm \mathrm{SD}$ ) of water and sodium $(A)$ and glucose, fructose, glycine, and lysine $(B)$ in C, HT, and HT\&T rats. There is a significant reduction of water, sodium, and glucose absorption and a diminished glycine transport in the HT rats; fructose and lysine transport is unaffected.

HT\&T and $C$ rats by 42 and $41.5 \%$, respectively, indicating a diminished $\mathrm{Na}, \mathrm{K}-\mathrm{ATPase}$ concentration in the mucosa of the HT rats (15).

Mucosal histology and ultrastructure. The histologic appearance of the jejunal mucosa was identical in the HT, HT\&T, and $\mathrm{C}$ rats. Electron microscopy showed no alterations in enterocyte arrangement, microvillar brush border, or intracellular organization in all three groups. However, in the HT rats, there was mild swelling of enterocyte mitochondria, with a widening of the cristae and a decrease in matrix density. Such mitochondrial swelling was not observed in HT\&T or C rats.

\section{DISCUSSION}

Evaluation of the influence of HT on small-intestinal absorption in patients and in intact animals is complicated by the multiple and often inconsistent alterations that HT may induce in each of the diverse determinants of gut function. In vitro studies of the effects of thyroid deprivation on epithelial transport, using models such as intestinal rings or everted sacs $(2,7$, $8,16)$, have often produced data that differ significantly from those obtained by in vivo investigations $(2,8)$. Moreover, the effect of thyroid hormones on intracellular respiration and metabolism is known to be biphasic-namely, modest doses of hormone will stimulate oxygen consumption and promote anabolism, whereas large doses will have the opposite effect, including alterations in carbohydrate and protein turnover and sodium transport (17). This phenomenon may account, in part, for the disparity between the various reports, as the magnitude of the hyperthyroidism or HT prevailing in the clinical or experimental situation may have dictated the outcome of the study. 


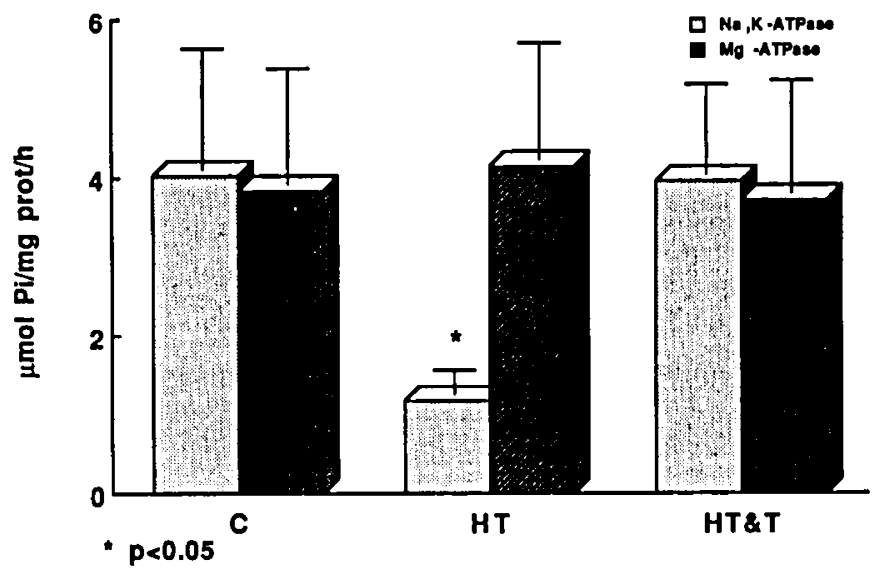

Fig. 3. Jejunal mucosal ATPase activity in the three groups of rats (mean $\pm \mathrm{SD}$ ). Activity of $\mathrm{Na}, \mathrm{K}-\mathrm{ATPase}$ was significantly lower in $\mathrm{HT}$ rats compared with HT\&T and $C$ rats.

Table 1. ATP-dependent $\left[{ }^{3}\right.$ HJouabain binding (mean $\pm S E M$ ) by jejunal mucosal homogenates from $H T, H T \& T$, and $C$ rats*

\begin{tabular}{llcr}
\hline Group & $n \dagger$ & $\begin{array}{c}B_{\max } \\
\text { (pmol/mg prot) }\end{array}$ & \multicolumn{1}{c}{$\mathrm{k}_{\mathrm{d}}(\mathrm{nM})$} \\
\hline HT & 16 & $3.15 \pm 0.11 \ddagger$ & $98 \pm 3$ \\
HT\&T & 15 & $5.42 \pm 0.12$ & $101 \pm 3$ \\
C & 17 & $5.39 \pm 0.22$ & $97 \pm 2$ \\
\hline
\end{tabular}

* Jejunal homogenates were incubated in a $10-\mathrm{nM}\left[{ }^{3} \mathrm{H}\right]$ ouabain-containing medium, in the presence of either $0,20,50,100,500$, or 1000 $\mathrm{nM}$ nonradioactive ouabain. ATP-dependent binding is the difference between $\left[{ }^{3} \mathrm{H}\right]$ ouabain binding in the presence and absence of ATP. Whereas the $k_{d}\left(\right.$ affinity ${ }^{-1}$ ) for ouabain was similar in all three groups, the number of binding sites $\left(B_{\max }\right)$ was significantly lower in the mucosal homogenates of the HT rats.

$+n=$ number of experiments.

$\ddagger p<0.02$ vs. HT\&T and C.

Whereas information derived from in vitro experiments may clarify the direct effect of HT at the tissue or the cellular level, in vivo studies are more likely to reflect events as they bear on the clinical situation. The experimental design of the present work allowed us to observe the effects of HT on the small gut by the concomitant study of absorption, enzyme activities, and morphology. We are unaware of a similar comprehensive approach in the literature, where reports address themselves mainly to the effects of HT on isolated or selected aspects of intestinal function, as studied by a diversity of in vitro and in vivo methodologies. In our experimental model, we perfused in situ a segment of proximal jejunum; we could thereby circumvent the confounding effects of altered gastric emptying and intestinal motility on the assessment of jejunal transport capacity in the HT rat. An established observation in rats that are rendered HT is a decreased rate of weight gain, which is regarded as an indication that HT has indeed been induced (18). In the present study, a putative untoward effect of HT on overall small-intestinal absorption could be discerned from the failure of our HT rats to gain weight-in spite of an apparently adequate food intake-and the onset of catch-up growth after initiation of thyroxine therapy. Although we failed to assess stool output in the different groups, it was noted that the cages of the HT rats were "messier" than those of HT\&T and C rats.

The jejunal perfusion experiments showed that, compared with the $\mathrm{C}$ rats, HT rats had significantly lower transport rates of water, sodium, and glucose, and a reduced (albeit not statistically significant) glycine absorption. On the other hand, HT did not alter the jejunal transport of fructose and lysine. These indings can be ascribed to the significantly diminished Na,K- ITPase activity in the mucosa of the HT rats; this enzyme governs the sodium-coupled transport of glucose and glycine, whereas fructose and lysine are not dependent on Na,K-ATPase for their absorption $(19,20)$. In addition to confirming a reduction in jejunal mucosal $\mathrm{Na}, \mathrm{K}-\mathrm{ATPase}$ activity, the present work reports for the first time the kinetics of the enzymatic alterations that were induced by HT. The reason for a diminished concentration of $\mathrm{Na}, \mathrm{K}-\mathrm{ATPase}$ in the homogenates from the HT rats' jejunal mucosa, as indicated by the reduced numbers of ATP-dependent ouabain binding sites, remains unclear. Preliminary experiments that we conducted rule out a nonspecific effect of methimazole on $\mathrm{Na}, \mathrm{K}-\mathrm{ATPase}$ activity. Our finding of a reduced enzyme concentration could therefore be a manifestation of decreased protein synthesis, or of an altered configuration of the protein molecule, due to the HT state. Although the constellation of derangements that we observed in our HT rats might have been due to malnutrition, it seems that its role was rather minor, because brush-border enzyme activities, mucosal morphology, and the transport of fructose and lysine were not different from controls. The pattern of jejunal mucosal response to HT in the present work bears a striking resemblance to the alterations in small-intestinal absorptive function that have been described to occur during mild-to-moderate hypoxia $(21,22)$. This leads us to speculate that the functional changes observed in our HT rats, which were reversed by thyroid supplementation, stem from underutilization of energy sources.

In effect, a substantial proportion of the stimulation of cellular oxygen utilization is associated with thyroid-mediated activation of $\mathrm{Na}, \mathrm{K}-\mathrm{ATP}$ ase and sodium transport in various tissues, including jejunal epithelium (23-26). In addition, thyroid hormone influences the oxygen "unloading" capacity of erythrocytes (27), with thyroid deprivation causing a "shift to the left" of the Hb-oxygen dissociation curve (28), whereby a hypoxia-like situation might be induced at the tissue level.

In conclusion, HT may reduce small-intestinal mucosal $\mathrm{Na}, \mathrm{K}$ ATPase activity, apparently in association with a diminished mucosal $\mathrm{Na}, \mathrm{K}-\mathrm{ATPase}$ concentration, and decrease Na,K-ATPase-associated absorption. An impairment of intestinal absorptive capacity and its nutritional consequences could be a contributing factor to growth delay in HT.

Acknowledgments. The authors thank Edith Cohen and Nahum Azaria for technical assistance.

\section{REFERENCES}

1. Miller LJ, Gorman CA, Go VLW 1978 Gut-thyroid interrelationships. Gastroenterology 75:901-911

2. Kowaleski K, Kolodej A 1977 Myoelectrical and mechanical activity of stomach and intestine in hypothyroid dogs. Am J Dig Dis 22:235-240

3. Gracey $M 1971$ Intestinal absorption in the contaminated small-bowel syndrome. Gut 12:403-410

4. Levin RJ 1969 The effects of hormones on the absorptive, metabolic and digestive functions of the small intestine. J Endocrinol 45:315-348

5. Middleton WRJ 1971 Thyroid hormones and the gut. Gut 12:172-177

6. Bogdanove KM, Lipner HJ 1952 Intestinal absorption of glucose in hypothalamic obesity. Proc Soc Exp Biol Med 81:410-412

7. Bronk JR, Parsons DS 1966 The influence of thyroid gland on amino acid accumulation and protein synthesis by rat small intestine in vitro. J Physiol 184:942-949

8. Raheja KL, Tepperman J, Tepperman HM 1977 Effect of hypothyroidism on in-vitro and in-vivo intestinal absorption in the chick (Gallus domesticus). Gen Pharmacol 8:227-230

9. Miller DL, Schedl HP 1970 Total recovery studies on nonabsorbable indicators in the rat small intestine. Gastroenterology 58:40-46

10. Davis JS, Gander JE 1967 A reevaluation of the Roe procedure for the determination of fructose. Anal Biochem 19:72-79

11. Dahlqvist A 1970 Assay of intestinal disaccharidases. Enzymol Biol Clin 11:5266

12. Bradford MM $1976 \mathrm{~A}$ rapid and sensitive method for the quantitation of microgram quantities of protein using the principle of dye binding. Anal Biochem 72:248-250

13. Kramer HJ, Backer A, Kruck $F 1974$ Inhibition of intestinal $\mathrm{Na}^{+}, \mathrm{K}^{+}$-ATPase in experimental uremia. Clin Chim Acta 50:13-18

14. Yamamoto S, Akera T, Kim D-H, Brody TM 1981 Tissue concentration of $\mathrm{Na}^{+}, \mathrm{K}^{+}$-adenosine triphosphatase and the positive inotropic action of ouabain in guinea pig heart. J Pharmacol Exp Ther 217:701-707 
15. Allen JC, Martinez-Maldonado M, Eknoyan G, Suki WN, Schwartz A 197! Relation between digitalis binding in vivo and inhibition of sodium, potassium adenosine triphosphatase in canine kidney. Biochem Pharmacol 20:7380

16. Levin RJ, Syme G 1971 Differential changes in the "apparent $\mathrm{K}_{\mathrm{m}}$ " and maximum potential difference of the hexose and amino acid electrogenic transfer mechanisms of the small intestine, induced by fasting and hypothyroidism. J Physiol 213:46P-48P

17. Hoch FL 1974 Metabolic effects of thyroid hormones. In: Greer MA, Solomon DH (eds) Handbook of Physiology, Section 7: Endocrinology. Vol III. Thyroid. Williams \& Wilkins, Baltimore, pp 391-412

18. Katsilambros N, Ziegler R, Schatz H, Hinz M, Maier V, Pfeifer EF 1972 Intravenous glucose tolerance and insulin secretion in the rat after thyroidectomy. Horm Metab Res 4:377-379

19. Christensen HN 1979 Exploiting amino acid structure to learn about membrane transport. Adv Enzymol 49:41-101

20. Stevens BR, Kaunitz JD, Wright EM 1984 Intestinal transport of amino acids and sugars: advances using membrane vesicles. Ann Rev Physiol 46:417433

21. Lifshitz F, Wapnir S, Teichberg S 1986 Alterations in jejunal transport and
$\left(\mathrm{Na}^{+}, \mathrm{K}^{+}\right)$-ATPase in an experimental model of hypoxia in rats. Proc Soc Exp Biol Med 181:87-97

22. Berant M, Alon U, Antebi D, Diamond E, Koerner H, Mordechowitz D 1986 Effects of nonischemic hypoxia on jejunal mucosal structure and function: study of an experimental model in dogs. Pediatr Res 20:1143-1146

23. Ismail-Beigi F, Edelman IS 1971 The mechanism of the calorigenic action of thyroid hormone. Stimulation of $\mathrm{Na}^{+}+\mathrm{K}^{+}$-activated adenosine triphosphatase activity. J Gen Physiol 57:710-722

24. Smith TJ, Edelman IS 1979 The role of sodium transport in thyroid thermogenesis. Fed Proc 38:2150-2153

25. Lin $\mathrm{MH}$, Akera $\mathrm{T} 1978$ Increased $\left(\mathrm{Na}^{+}, \mathrm{K}^{+}\right)$-ATPase concentrations in various tissues of rats caused by thyroid hormone treatment. J Biol Chem 253:723726

26. Liberman UA, Asano Y, Lo CS, Edelman IS 1979 Relationship between $\mathrm{Na}^{+}$. dependent respiration and $\mathrm{Na}^{+}+\mathrm{K}^{+}$-adenosine triphosphatase activity in the action of thyroid hormone on rat jejunal mucosa. Biophys J 27:127-144

27. Miller WM, Delivoria-Papadopoulos M, Miller L, Oski FA 1970 Oxygen releasing factor in hyperthyroidism. JAMA 211:1824-1826

28. Grosz HJ, Farmer BB 1969 Reduction-oxidation potential of blood determined by oxygen releasing factor in thyroid disorders. Nature 222:875-876 